\title{
COMPUTER SCIENCE QUALIFYING EXAM: A CASE STUDY ON IMPROVING STUDENT SUCCESS AND PROGRAM QUALITY
}

\author{
EXAMEN DE CALIFICACIÓN DE CIENCIAS DE LA COMPUTACIÓN: \\ UN ESTUDIO DE CASO PARA MEJORAR EL ÉXITO DEL ESTUDIANTE \\ Y LA CALIDAD DEL PROGRAMA
}

Prateek Basavaraj, Mahlagha Sedghi', Ivan Garibay ${ }^{1 *}$,
Ozlem Ozmen Garibay', Arup Ratan Guha ${ }^{1}$

RECEPCIÓN: 05 DE NOVIEMBRE DEL 2019

ACEPTACIÓN: 03 DE DICIEMBRE DEL 2019

\begin{abstract}
Higher education institutions traditionally measure student success and quality of an academic program by standard metrics such as the time that takes a student to obtain a degree, graduation rates, and retention rates. Also, some programs have instituted a "qualifying exam" as an alternative way to measure the quality of an academic program and to assess student's mastery in core concepts. The Computer Science (CS) program at the University of Central Florida implemented a qualifying exam 'Foundation Exam' in 1998 with the purpose of assessing the students' mastery of CS core concepts and to control program quality. However, the pass rates of the students taking this qualifying exam were significantly and consistently low over the years. Also, some students systematically delayed taking this exam due to the fear of failing. To reflect the knowledge credentials needed by industry, promote mastery of core CS concepts and help students to graduate in a timely manner, data-driven recommendations for improvement were implemented in 2016. After the improvements were made, many more students attempted the exam on time and made progress in their degree in the years 2016-2018. The details of these improvements and their impact are presented in this paper.
\end{abstract}

Keywords: STEM, higher education, qualifying exams, graduation and retention rates, student success, program curriculum.

\begin{abstract}
RESUMEN
Lasinstituciones deeducación superior tradicionalmente miden el éxito de los estudiantes y la calidad de un programa académico mediante métricas estándar, como el tiempo que tarda un estudiante en obtener un título, las tasas de graduación y las tasas de retención. Además, algunos programas han instituido un "examen de calificación" como una forma alternativa de medir la calidad de un programa académico y evaluar el dominio del estudiante en los conceptos básicos. El programa de Ciencias de la Computación (CS) de la Universidad de Florida Central implementó un examen de calificación "Examen básico" en 1998 con el propósito de evaluar el dominio de los estudiantes de los conceptos básicos de CS y controlar la calidad del programa. Sin embargo, las tasas de aprobación de los estudiantes que tomaron este examen de calificación fueron significativamente bajas a lo largo de los años. Además, algunos estudiantes retrasaron sistemáticamente la realización de este examen por temor a reprobar. Para reflejar las credenciales de conocimiento que necesita la industria, promover el dominio de los conceptos básicos de informática y ayudar a los estudiantes a graduarse de manera oportuna, se implementaron recomendaciones de mejora basadas en datos en 2016. Después de que se realizaron las mejoras, muchos más estudiantes intentaron el examen a tiempo y progresaron en su título en los años 2016-2018. Los detalles de estas mejoras y su impacto se presentan en este documento.
\end{abstract}

Palabras clave: STEM, educación superior, exámenes de calificación, tasas de graduación y retención, éxito de los estudiantes, plan de estudios del programa.

1 University of Central Florida. * Corresponding author: Ivan Garibay, igaribay@ucf.edu, Department of Industrial Engineering and Management Systems, College of Engineering and Computer Science, University of Central Florida, 4000 Central Florida Blvd., Orlando, FL 32816, USA 


\section{INTRODUCTION}

Student success is a widely discussed topic in higher education $[1,2]$. It is measured by metrics such as graduation rates, retention rates, and time to degree. In recent years, higher education institutions have been emphasizing more on improving these success metrics of its programs by implementing a variety of evidence-based institutional practices and reforming existing policies. Various degree programs use different criteria to qualify their students for graduation, which directly affects their graduation rates. Some programs allow students to graduate if they pass all courses in the program curriculum whereas other programs not only require their students to pass all courses but also to meet some program-specific requirement. That is, sometimes, program-specific factors are used to assess the knowledge of students in the program's core concepts to ensure their clear understanding of these concepts. For example, the electrical engineering program at the San Jose State University has a skill audit exam as their program-specific factor to assess the mastery of core concepts in electrical engineering [3]. Similarly, the Computer Science (CS) program at the targeted university, has a program-specific factor, which is a qualifying exam for students enrolled in the CS program. Another important reason for having this exam is that faculty who teach advanced level courses believe that the exam helps them to teach advanced courses without having to spend additional time to explain basic CS concepts to students. The original qualifying exam used to test students' knowledge and understanding in two CS core courses: Computer Science -1 and Discrete Structures.

Both four- and six-years graduation rates of the CS program at the targeted university stayed low until 2015. We hypothesize that the reason for this is the program's requirement to pass the exam before taking any advanced level courses in the curriculum. The enrollment of the CS program has been increasing over the years, but the graduation rates stayed consistently low [1]. It is important to understand whether and how the qualifying exam affects student outcomes. Therefore, the following research questions were defined to guide this study:

a) What program policies related to the qualifying exam and the program curriculum affect student success in the CS program at the targeted university?

b) What policies do other programs with a similar qualifying exam may have to consider in improving the graduation rates and program quality?

To do this, institutional data of 2008 - 2015 student cohorts of the CS program at the targeted university were analyzed. It was clear that the qualifying exam was a barrier for students to graduate. This study investigated the underlying causes and provided recommendations to improve the success rate of the exam and the program overall. After implementing these recommendations, the CS department under study observed an improvement in its exam pass rates and the graduation rates of the program according to data for years 2016 to 2018.

\section{QUALIFYING EXAMS IN HIGHER EDUCATION INSTITUTIONS: EXISTING RESEARCH}

Related literature studies the assessment process of a variety of schools and programs using different qualifying exams. These evaluations are mainly inspired and required by a unified theme of the Technology Accreditation Commission of the Accreditation Board for Engineering and Technology (TAC/ABET) in the United States.

Mechanical Engineering Technology (MET) and Computer Integrated Manufacturing Technology degree programs at Indiana University - Purdue University Indianapolis (IUPUI) have a graduation exam. Rennels and Zecher [4] study how this exam affects the curriculum enhance- 
ments and conduct statistical analysis of the results using grade point average and time to graduation variables. Similarly, Goldberg and Jay [5] study how to identify thorough and informative measures of performance, and proper assessment tools for the senior design course for biomedical engineering programs, such that they produce the desired ABET learning outcomes. To consider ABET's criteria into account, the CS department of King Fahd University of Petroleum and Minerals has also modified their academic curriculum. Rao et al. [6] report the resulting changes in the curricular activities as well as assessment tools, and the existing challenges. Similarly, Rabaa'i et al. [7] presented the design and implementation process of student outcome assessments for Computer Science and Information Systems Department at the American University of Kuwait. Three different indicators are reported as a performance measure, whose different aspects are discussed including data collection, assessment tools, analysis, and recommendation procedure.

Furthermore, the Electrical Engineering program at San Jose State University has a 'skill audit exam' [3]. Due to low scores, the department made improvements to this exam. Introducing an online review exam and replacing the existing audit exam with an in-class one has shown improvements in the students' incentive to prepare for the exam, and consequently, better scores on the exam. The capstone senior design course for Mechanical Engineering programs typically reflects the ABET criterion implementation which is specifically structured to assess achievement of student outcomes of these programs. The assessment is usually through evaluating assignments that form the engineering design procedure [8]. The data corresponding to six semesters of senior exams was analyzed to identify the subject materials and the related course that pose serious challenges for students [9]. Based on these observations, the employed methods for providing insightful modification plans to improve the MET program were discussed.

Most existing studies either changed their program curriculum to consider the ABET criterion or used first-year academic performance as a criterion measure. To our knowledge, there are no studies using outcomes such as student mastery levels, exam passing rates, and graduation rates. Furthermore, there is only one study [3] in which some changes were made to the exam and evaluated student mastery levels in core concepts. To address these shortcomings in the literature, this study focused on reflecting the existing policies related to the exam and evaluating student mastery levels of the program's core concepts and exam passing rates after policy changes were made.

\section{The Target University}

The university targeted in this study is one of the largest universities in the United States with regard to student enrolment. CS program is housed along with Information Technology program in the department of Computer Science. CS department is among the top five largest departments within the university. CS undergraduate program at this university is accredited by ABET. Students are typically admitted to CS programs based on standardized test scores (e.g. Scholastic Assessment Test (SAT)) and the Grade Point Average (GPA) achieved at high school or previous institution.

\section{ORIGINAL COMPUTER SCIENCE QUALIFYING EXAM AT THE TARGETED UNIVERSITY}

The original qualifying exam used to test students' knowledge in two core CS courses: Discrete Structures and Computer Science-1. The exam consisted of a total of four parts (Computer Science-1: Part - A and Part - B, and Discrete Structures: Part- A and Part-B). Both parts A and B of Computer Science-1 consisted of five questions each from data structures, design and analysis of algorithms whereas, part A of Discrete Structures consisted of four questions from sets, number theory, induction, 
and logic, and part B consisted of four questions on counting, probability, functions, and relations. Students were required to answer all questions, and there were no choices. A faculty who oversees the exam evaluates solutions based on the completeness of the solution steps. Students had to get passing scores in both Computer Science- 1 and Discrete Structures sections. However, this scoring scheme was flexible in some cases where students earn a full score in either one and less than a passing score in another course.

Previously, students could take the exam as many times as needed until they passed it. To avoid delay in taking the exam, the department recommended students to take Discrete Structures and Computer Science-1 courses in the same semester and attempt the exam right after the semester they pass these courses. This exam is typically offered at the beginning of each semester and students had to sign up online prior to the exam day if they decide to take the exam in a semester.

\section{METHODOLOGICAL APPROACH OF DATA-DRIVEN DECISION MAKING IN EDUCATION}

This study utilized institutional data of CS students who were enrolled in the enrolled in the CS program at the targeted university during academic years 2008 to 2015 to take measures to improve the success rates of CS foundation exam using a conceptual framework for data-driven decision making in education [10]. The institutional data consisted of students' course history, term-to-term enrolment information, degree, and dropout information. The conceptual framework used in this study was adapted from Gill et al. [10] and consisted of three main components as summarized in Figure 1: assemble high-quality raw data, analyse to ensure data is relevant and diagnostic, and use this data to inform instructional and operational decisions.

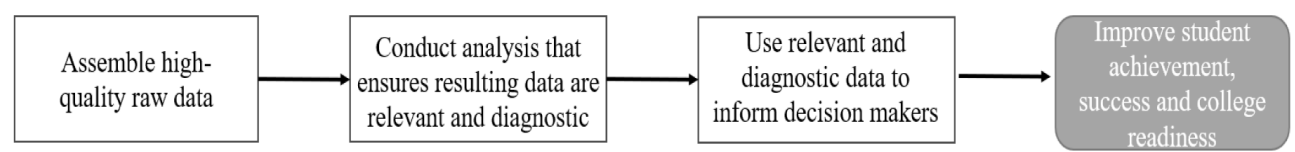

Figure 1. Conceptual framework for data-driven decision making in education (adapted from Gill et al. [10])

Using the conceptual framework, the process of data-driven decision making began by pulling student data from institutional data storage systems. The analysis began by becoming familiar with multiple data points in the dataset to guide the study. Once the institutional data was extracted from storage systems, data was cleaned and examined thoroughly to determine data points that were suitable for our analysis to ensure that they were aligned with the goals of the analysis.

Once the analyses were completed, the data points that were determined to impact the success rates of qualifying exam were used to make decisions related to exam and program policies. Also, faculty inputs of the CS program were considered in making decisions related to program curriculum.

\section{IMPROVEMENTS TO THE CS QUALIFYING EXAM}

Several changes were made to the qualifying exam in 2016 to allow CS students to reflect more accurately the knowledge expected of them before they were designated as a CS-ready. The intent was also to help students to make early decisions about their major and to advance in their degree program. These changes were made based on faculty input and thorough analyses of institutional data of CS students. These changes were focused mainly on two goals. The first goal was to help students graduate 
in a timely manner and provide major transition advising to at-risk students who had failed the exam. The second goal was to help students to master CS core concepts before they graduate.

The improvements made to help students to graduate on time consisted of limiting the number of attempts to pass the exam. With this new restriction on limits of attempting the exam, students can take the exam maximum three times before they pass. This restriction is based on historical data analysis. CS institutional data indicate that a vast majority (96\%) of students passed the qualifying exam within three attempts and that their success rate reduces as the number of attempts increases. Due to the lack of restrictions in the original exam, some capable students skipped taking the exam multiple times, and other students who were likely a better fit for a different major delayed their start in that other major by taking the CS qualifying exam many times.

Another set of improvements were made to help students to master key CS skills that would benefit students in their career-related prospects. CS faculty identified 'Computer Science-1' as the most important skill to be tested in the exam that would help students to pass advanced level courses and graduate early. The faculty also wanted to change the prerequisites for the Discrete Structures class, adding calculus as a prerequisite. For these reasons, the CS department changed the structure of the exam in 2016. The new exam consists of a total of two parts (Computer Science - 1: Part A: CS- Data Structures and Part B: CS- Algorithms and Analysis Tools). Each part consists of six questions and students are required to answer all questions. The passing line for the exam is based on the relative score and set by the faculty who oversees the exam. The expertise in Computer Science-1 course is necessary to pass the exam, and UCF-CS institutional data shows that the majority of students $(72 \%)$ with grades better than B (3.0) in this course pass the qualifying exam in one attempt. As a result, it was necessary to take measures to improve the success rates of the Computer Science- 1 course. So, the CS department increased the number of graduate teaching assistants, graduate teaching graders, and undergraduate teaching assistants to help students with their coursework. Also, to identify students who need additional help to succeed in the program, the department started conducting tests or quizzes early in the semester and assign extra study sessions for at-risk students. Also, some faculty set up an automatic checker for exercise problems and created quizzes on the web management system for big-O notation concepts.

The new exam tests students' knowledge in data structures, algorithms and analysis tools. The new exam is made simple in terms of topics covered and has reduced the burden for students to take a long duration exam. The new exam length is two hours, whereas the old exam duration was three hours. This new exam is efficient in testing students' understanding of key program-specific topics. The twelve-question in-class exam measures students' mastery of CS core concepts. The pass or fail grading of exam motivate students to put in extra work and ensure that they will study until they pass it [3]. This exam is a zero-credit exam and does not contribute to students' Grade Point Average (GPA).

\section{RESULTS OF THE IMPROVEMENTS}

The department carried out this study in 2015 (Spring 2015, Summer 2015 and Fall 2015) and changes were implemented to the original exam in Fall 2016. The data of eight semesters (Fall 2016, Spring 2017, Summer 2017, Fall 2017, Spring 2018, Summer 2018, Fall 2018, and Spring 2019) were analyzed to evaluate students' mastery levels and their degree progress since the changes were made to the original qualifying exam. The sample size for each semester was greater than 200 . 


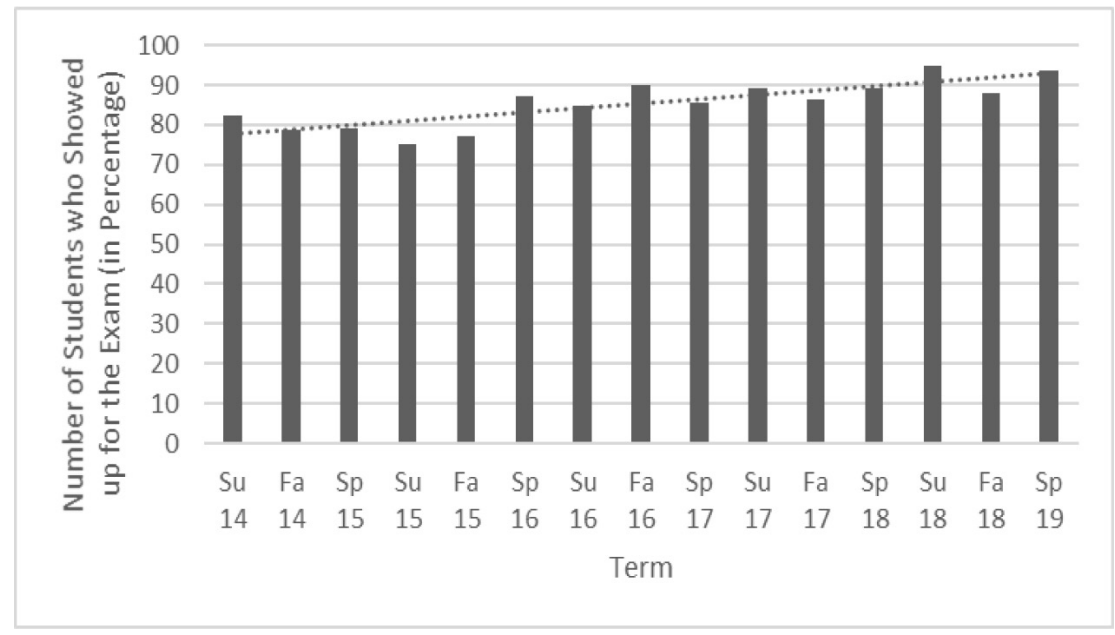

Figure 2. Term-wise Exam Show up Rate of CS Qualifying Exam

As mentioned above, limiting the number of attempts to pass the exam was introduced to the original exam. A thorough investigation was done to understand and clarify whether this new improvement had helped students to attempt the exam. The number of students who showed up for the exam after the improvements were made has increased over the years (as shown in Figure 2). The average percentage of students who showed up in original (or old) and new exams after signing up online were $80 \%$ and $90 \%$ respectively. There is an increase in the number of students showing up for the exam after signing up. After new rules were imposed, around $90 \%$ of students who signed up took the exam. In the original exam (for terms from Summer 2014 to Summer 2016), around 78.73\% of students who were eligible to take the exam attempted the exam. Out of which only $42.31 \%$ of students passed the original exam. Due to the improvements, there is an increase in the number of students attempting the exam. As a result, there is an increase in the average pass rate of the exam (50.6\%). The exam pass rates after the improvements were made for term Fall 2016 and academic years 2017 and 2018 were $47.8 \%, 48.63 \%$, and 51.86 respectively (Figure 4 and Figure 5). There is an improvement in the exam passing rates. Previously, the passing rates of exam stayed between $35 \%$ and $44 \%$ (2014: 38.5\%; 2015: 42.6\%; Spring 2016 and Summer 2016 combined: 44\%) (Figure 3).

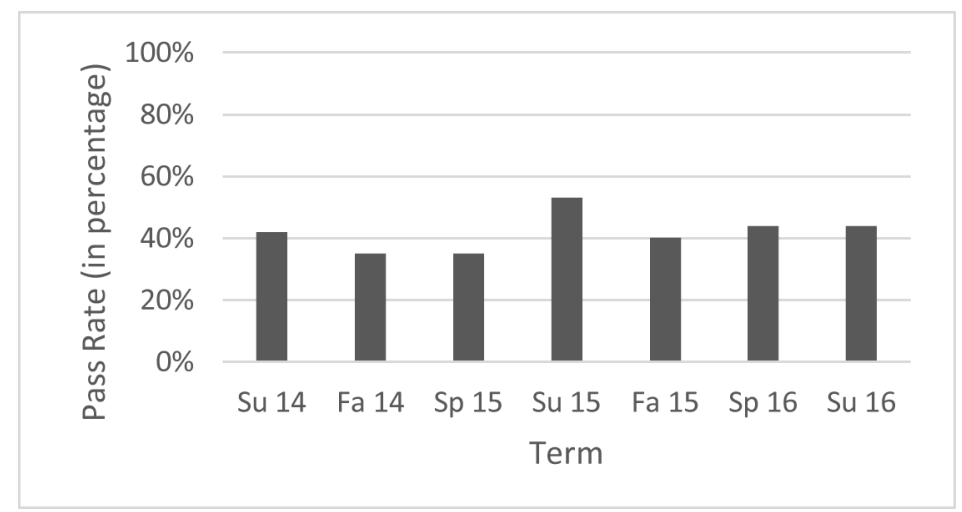

Figure 3. 2014 to 2016 Pass Rates of CS Qualifying Exam 
There is an increase in the number of students who passed the new exam otherwise who would have not passed in the original qualifying exam. As mentioned earlier, around $78.73 \%$ of 2026 students attempted and $42.31 \%$ of students passed the original exam. If the same passing rate was assumed for 2313 students (who were eligible to take the exam during Fall 2016 and beyond) under a new exam, then 771 students were expected to pass $(0.7873 * 0.4231 * 2313 \sim 771$ students $)$ but instead 1054 students passed the new exam. Thus, there were around 283 students $(1054-771=283$ students) who passed the exam otherwise who would have not passed the original exam. Thus, there was a $36.7 \%$ increase in CS students that can be attributed to the exam changes. Thus, there is an increase in the number of students taking the exam in 2017-18 and 2018-19. 1103 students took the exam in 2016-17, 2017-18 and 2018-19 for the first time. This number is the highest in the last ten years.

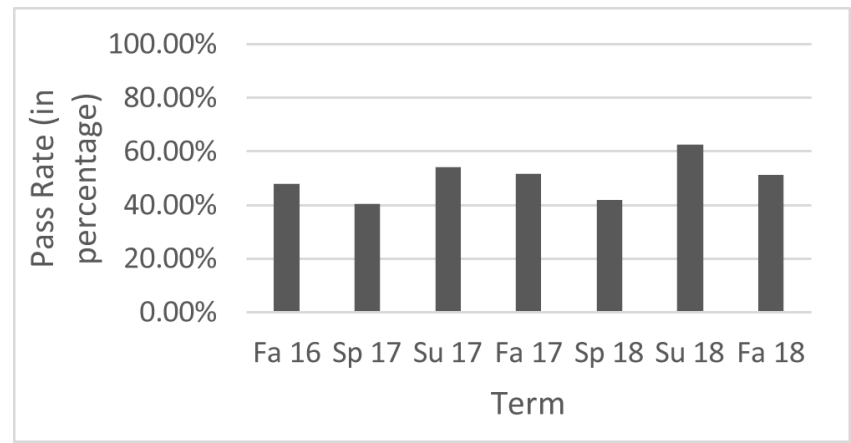

Figure 4. Term wise Pass Rates of CS Qualifying Exam

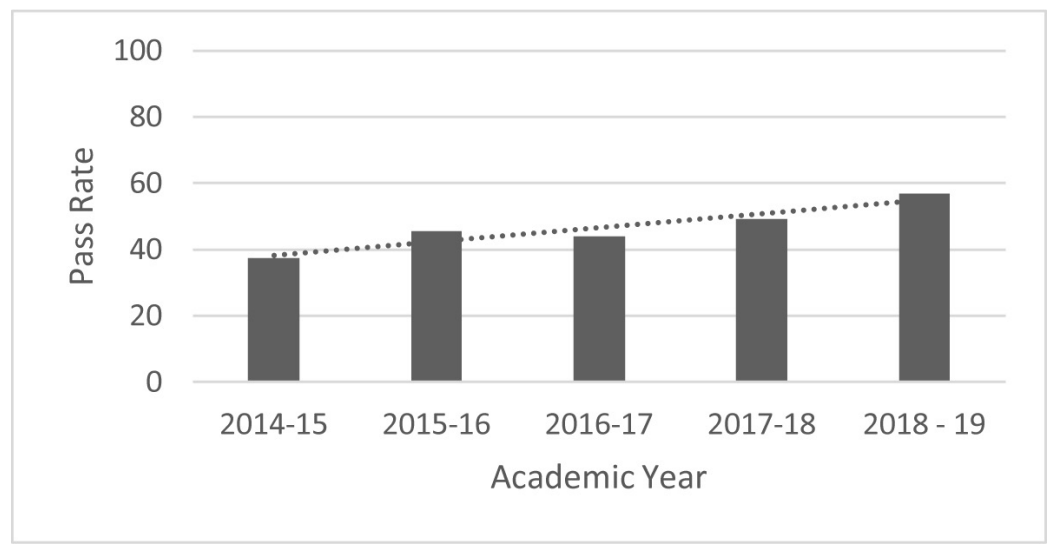

Figure 5. Year-wise Pass Rates of CS Qualifying Exam

Out of 1103 students, $74 \%$ of students passed the exam. 543 (67\%) of students passed the exam in the first attempt, 24\%, 9\% of students passed in second and third attempts respectively.

Prior to the intervention, many students used to take the exam multiple times until they pass, which eventually resulted in increased dropout and major-transition (change of major) rates. Students used to spend one to two years or sometimes more in the CS program before they decide to drop out or change majors. This resulted in delayed graduation and low graduation rates. Thus, the original qualifying exam which used to act as a barrier for students to graduate, is now made flexible and streamlined for students to graduate. 


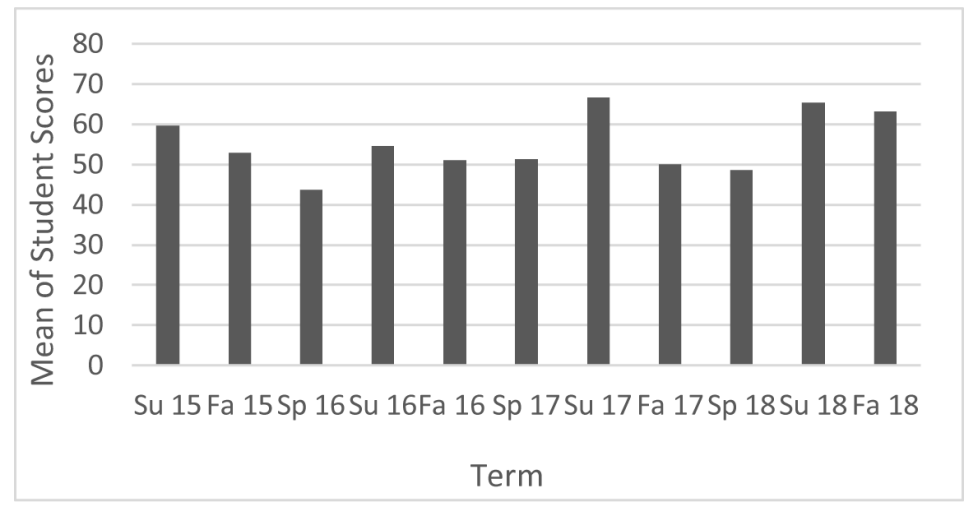

Figure 6. Student mastery levels in Computer Science-1

Another goal of this study was to improve the students' mastery levels in CS core concepts. The mean scores of students' mastery levels in core sections of the exam such as data structures, algorithms, and analysis tools have improved in Summer 2017, Summer 2018, and Fall 2018 semesters whereas it remained the same in Fall 2016, Spring 2017, Fall 2017, Spring 2018 since changes to the exam were made (Figure 6 and Figure 7). This may be due to (i) the difficulty level of exam varies from semester to semester and is dependent on the faculty member who sets exam questions; (ii) the passing score (which is set by the faculty in charge of the exam) varies from semester to semester. Besides, students perform well in data structures compared to algorithms and analysis tools (Figure 7).

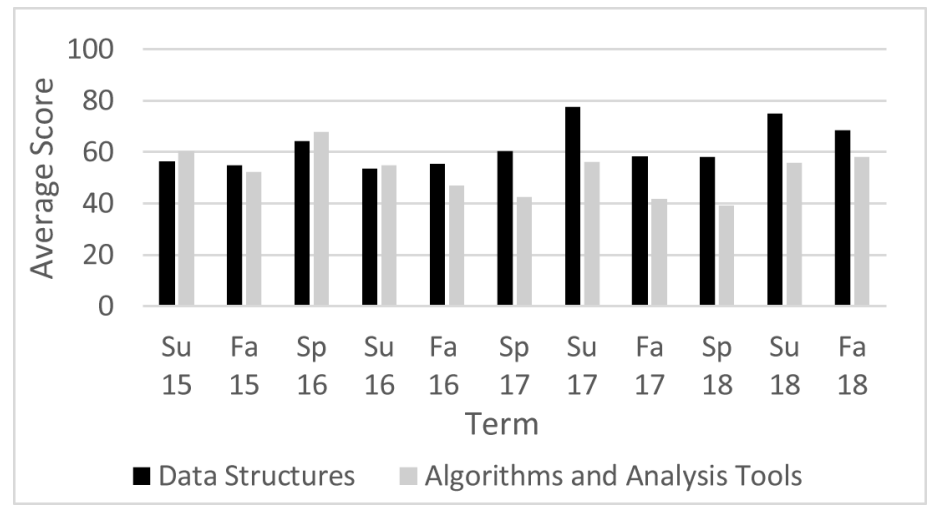

Figure 7. Student mastery levels in core content areas

The CS qualifying exam is a direct prerequisite for four advanced levels CS mandatory courses (processes for objected-oriented software development, senior design 1 and 2, discrete computational structures) (Figure 8). Students can only take these courses after passing the exam. Students' graduation is dependent on completing the aforementioned courses and remaining electives after passing the qualifying exam. CS historical data showed that $94 \%$ of students who passed the exam graduated with a CS degree. Before the intervention, students used to take the exam repetitively till they pass it and most of them ended up dropping out of the college. Also, those who passed the exam took a minimum of four and a maximum of eight terms to graduate (before the intervention). 


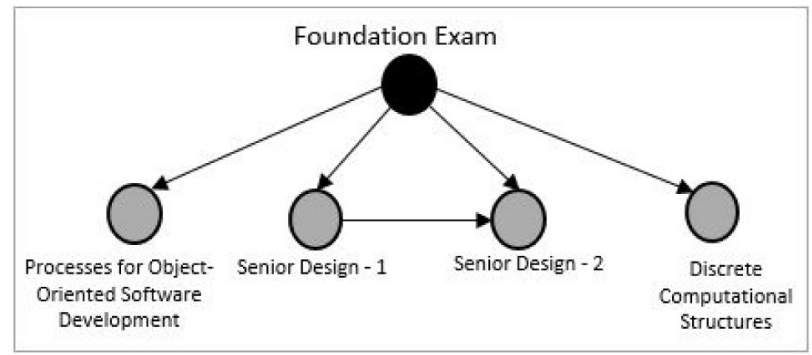

Figure 8. 'Qualifying Exam' as a Pre-requisite for four advanced level CS courses

After implementing changes to the original qualifying exam, the number of students attempting the exam has increased (Figure 9). Also, the number of students graduated in semesters Fall 2016, Spring 2017, and academic year 2017-18 (Summer 2017, Fall 2017, Spring 2018) were 62, 81 and 260 respectively. The number of students who graduated in 2017-18 is an all-time high in the last six years compared to 2014-15 (154 students graduated), 2015-16 (177 students graduated). However, the number of students graduated in 2017-18 may include students who passed the original (or old) qualifying exam. So, we measured how many students have graduated after passing the new qualifying exam and their time to degree. Out of 151 students who passed the exam in Fall 2016, 60 students (40\%) graduated and the remaining 91 students (60\%) are still in the program. Out of these 60 students, 7 students graduated in Summer 2017 ( $2^{\text {nd }}$ term after passing the exam), 12 students graduated in Fall 2017 ( $3^{\text {rd }}$ term after passing the exam), 25 students graduated in Spring 2018 ( $4^{\text {th }}$ term after passing the exam), 9 students graduated in Summer 2018 ( $5^{\text {th }}$ term after passing the exam) and 16 students graduated in Fall 2018 ( $6^{\text {th }}$ term after passing the exam). Table I shows the term-wise representation of students' graduation term after passing the new CS qualifying exam. Therefore, it takes a minimum of two and a maximum of six terms for students to graduate after passing the new qualifying exam (Table I). The changes implemented to the original exam have helped to graduate a greater number of students in 2017-18. But before the intervention, the number of CS students graduated remained the same over the years from 2005-06 to 2016-17 whereas the number of students joining the CS program (or CS enrollment) has been increasing (Basavaraj et al. 2018).

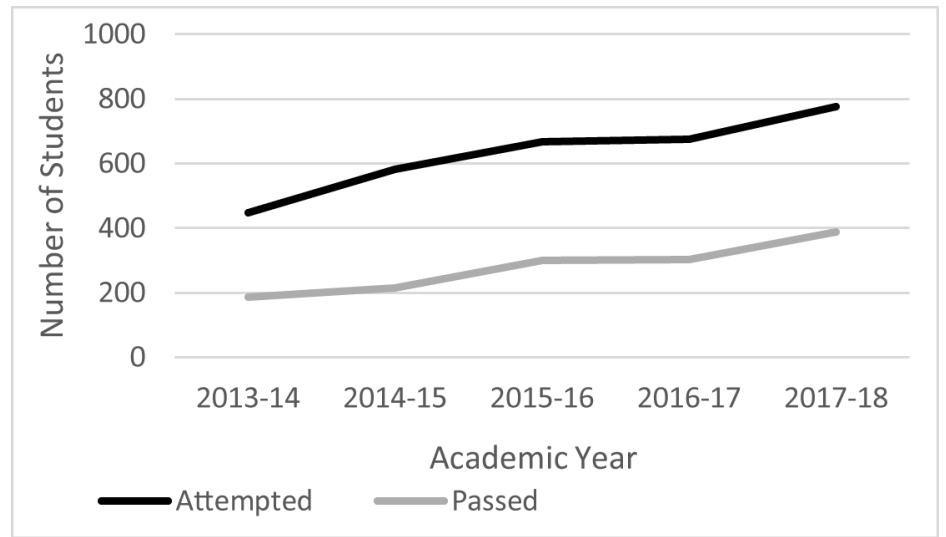

Figure 9. Number of Students who attempted and passed the exam 
TABLE I. Number of students graduated after passing the new CS qualifying exam

\begin{tabular}{|l|l|}
\hline \multicolumn{1}{|c|}{$\begin{array}{c}\text { Term when Students Pass the } \\
\text { Exam }\end{array}$} & \multicolumn{1}{|c|}{$\begin{array}{c}\text { Number of Students Graduated } \\
\text { [Term (Total Students) ...] }\end{array}$} \\
\hline Fa16 & $60[$ Fa17(12), Sp18(25), Su17(7), Fa18(16), Su18(9) \\
\hline Sp17 & $27[$ Sp18(15), Su18(7), Fa18(5)] \\
\hline Su17 & $34[$ Sp18(8), Fa18(15), Su18(11)] \\
\hline Fa17 & $10[$ Su18(4), Fa18(6)] \\
\hline
\end{tabular}

\section{MAJOR TRANSITION ADVISING}

Due to the new advancement of allowing students to attempt the exam for a maximum three times, students who failed to pass the exam even after taking the exam three times were given the option of changing their major from CS to other programs. This transition process is made smooth to allow students to choose their desired major other than CS. As per 2016-17 and 2017-18 cohorts, there were only 22 students who failed to pass the exam in three attempts. These students were recommended to change their major to Information Technology (IT) program. However, students have the option to choose their desired major.

Prior to the intervention, most students $(70 \%)$ who failed the exam changed their major to IT program and $90 \%$ of them ended up getting a degree in IT. Also, the IT curriculum shares seven similar courses with CS. Students don't have to take all courses from the beginning and have the flexibility of transferring CS courses. Also, CS majors who failed the exam transfer to other programs such as digital media (7\%), interdisciplinary studies (3\%), computer engineering (3\%), and psychology (3\%).

There has been a lot of debate on whether exit exams are helpful for students or not [11]. However, the main goal of the CS qualifying exam is to evaluate students' knowledge of core topics in CS and prepare them for the workforce. Students with a GPA greater than or equal to 2.0 are eligible to take the exam. Out of the 22 students who failed to pass the exam in three attempts, 12 (55\%) students had cumulative GPA less than 3.0, 10 (45\%) students had GPA greater than 3.0. It was surprising to see two students with a GPA above 3.5 failed to pass the exam. There has been a lot of debate in the educational community about whether the grades are the right measure of students' learning or not [12]. In the midst of all these debates, some institutions have qualifying exams which act as a catalyst to enhance the program quality and to prepare students for the competitive workforce. Qualifying exams act as an effective metric to measure student learning in higher education. There is a positive impression within the college community about the CS qualifying exam. Students in other programs think that the CS program is highly recognized, and even their program should have qualifying test like CS qualifying exam (Basavaraj et al. 2018). Even some believe that programs should have a qualifying test to help students decide their right major (Basavaraj et al. 2018). Overall, the CS qualifying exam is serving as a program quality enhancer.

\section{DISCUSSION}

This study utilized the conceptual framework of data-driven decision making in education to implement data-driven interventions to improve the success rates of CS qualifying exam. Historical data analyses showed that some students were not attempting the exam due to the fear of failing the exam, and some students who were better fit for other majors delayed their start in that program by 
taking the exam multiple times. The CS program experienced more volatility in terms of students not attempting the exam and staying in the program longer than usual. This implies a higher level of rigor in the program to some extent. CS program was more rigid in its program curriculum because of a greater number of prerequisites, which may be causing delayed graduation [1]. The CS qualifying exam was acting as a barrier for CS students to continue in their program. This finding is aligned with the previous research from Valli and Johnson [13] on the entrance examinations for teacher education.

After introducing new program policies such as introducing the maximum limit (number of attempts), changing the structure of the qualifying exam, making curriculum changes (adding calculus requirement for Discrete Structures class), there is an increase in the number of students attempting the exam. As a result, there is an increase in the number of students passing the exam. The graduation rates of CS program are dependent on the success rates of the qualifying exam. These changes resulted in the streamlined flow of students towards graduation. Also, there is not much change in the mastery levels of CS students in core program areas in both original and new qualifying exam. This suggests that the significant goals of the exam to test students' knowledge in core concepts were consistently maintained.

Based purely on institutional data analyses, the CS program demonstrated an improved level of student success in terms of exam success and graduation rates after implementing new policies. Consistent with the findings of Parent [3], this study demonstrated that the success rates of qualifying exams can be improved by changing or updating existing policies related to the exam and program in addition to making some curricular changes. The results of this study demonstrate that changes in the program curriculum and policy changes were crucial for improving student success of academic programs.

One of the main goals of most qualifying exams was to assess students' mastery in the program's core concepts $[13,3]$. It is important for institutions to determine what topics (or concepts) were most important that would help students in their jobs and evaluate students' knowledge based on those topics. Also, it is important to reflect on current policies related to exam and a program to determine possible reasons that improves student success. It is clear from this study that changing policies related to exam and program based on institutional data helped to improve the success rates of CS qualifying exam. This study determined that allowing students to take the qualifying exam innumerable number of times resulted in low graduation rates and high dropout rates. This finding is consistent with the Tinto [14] and Astin [15] studies on student retention and graduation, which states that students who stay longer in college tend to drop out at higher rate. So, introducing the maximum limit on the number of attempts would help to allow students to graduate in a timely manner (within six-years in United States).

Qualifying exams serve the purpose of maintaining the quality of academic programs. It is important for institutions to allocate program resources in terms of increasing the number of graduate teaching assistants, graduate teaching graders, and undergraduate teaching assistants to support students in core courses to clarify their doubts or questions in core concepts. Increasing the program resource allocation would positively impact the success rates of the qualifying exam. The results of this study showed that reflecting on existing policies related to academic program and the curriculum help to reduce challenges of student success and to improve the program quality.

\section{CONCLUSION}

The improvements made to the CS qualifying exam (which included limiting the number of attempts to pass the exam and changing the structure of the exam) has allowed many students to attempt the 
exam and master the core CS concepts before they graduate, which has a positive consequence in their job performance or graduate schools. Limiting the number of attempts helped students to take the exam and progress towards their graduation. Two years after the improvements were implemented, there is an increase in the graduation rates of the CS program. Additional improvement that needs to be implemented in the near future is to allocate extra resources (such as tutors or extra sessions) to improve students' performance in the algorithms and analysis tools section of the exam.

\section{Acknowledgment}

This work is partly funded by the Board of Governors - Targeted Educational Attainment (TEAm) Grant: An Urban University Coalition Response to Florida's Computer and Information Technology Workforce Needs.

\section{REFERENCES}

[1] P. Basavaraj, K. Badillo, I. Garibay and P. J. Wisniewski, "A Tale of Two Majors: When Information Technology is Embedded within a Department of Computer Science.," in In Proceedings of the 19th Annual SIG Conference on Information Technology Education (pp. 32-37), Fort Lauderdale, 2018.

[2] L. Thomas, "Student retention in higher education: the role of institutional habitus." Journal of education policy, pp. 423-442., 2002.

[3] D. W. Parent, "Improvements to an Electrical Engineering Skill Audit Exam to Improve Student Mastery of Core EE Concepts," IEEE Transactions on Education, vol. 54, pp. 184--187, 2011.

[4] K. \&. Z. J. Rennels, "Student Learning Assessment in Engineering Technology Programs with a "Graduation Exam"," age, vol. 1, 2003.

[5] J. R. Goldberg, "Senior design capstone courses and ABET outcomes," IEEE Engineering in Medicine and Biology Magazine, vol. 25, pp. 84--86, 2006.

[6] K. Rao, S. Junaidu, T. Maghrabi, M. Shafique, M. Ahmed and K. \& Faisal, "Principles of curriculum design and revision: a case study in implementing computing curricula CC2001," in $A C M$ SIGCSE Bulletin 37, no. 3 (2005): 256-260., 2005.

[7] A. A. Rabaa'i, A. R. Rababaah and S. A. \& Al-Maati, "Comprehensive guidelines for ABET accreditation of a computer science program: the case of the American University of Kuwait," International Journal of Teaching and Case Studies, vol. 8, no. 2-3, pp. 151-191, 2017.

[8] V. Wilczynski and A. C. Foley, "Designing a Capstone Design Course to Achieve Student Outcomes," in ASME 2014 International Mechanical Engineering Congress and Exposition, 2014.

[9] P. Yearling, T. Anderson and R. Durkin, "IUPUI mechanical engineering technology senior assessment," in ASEE Annual Conference and Exposition, 2017.

[10] B. Gill, B. C. Borden and a. K. Hallgren, "A conceptual framework for data-driven decision making.," Final Report of Research conducted by Mathematica Policy Research, Princeton, submitted to Bill \& Melinda Gates Foundation, Seattle, WA., 2014.

[11] K. J. Sullivan, “"In new study, high school exit exam gets a failing grade,", 21 April 2009. [Online]. Available: https://news.stanford.edu/news/2009/april22/california-exit-exam-042209. html. [Accessed 21 March 2019].

[12] N. Nagappan, L. Williams, L. Williams, M. Ferzli, E. Wiebe, K. Yang, C. Miller and S. and Balik, "Improving the CS1 experience with pair programming.," In ACM SIGCSE Bulletin., vol. Vol 35, no. ACM, pp. 359-362, 2003. 
[13] R. Valli and a. P. Johnson, "Entrance examinations as gatekeepers.," Scandinavian Journal of Educational Research, pp. 493-510., 2007.

[14] V. Tinto, "Stages of student departure: Reflections on the longitudinal character of student leaving.," The journal of higher education, pp. 438-455., 1988.

[15] A. W. Astin, "Student involvement: A developmental theory for higher education.," Journal of college student personnel, pp. 297-308., 1984.

[16] M. a. B. L. .. Yorke, Retention and student success in higher education, UK: McGraw-Hill Education, 2004.

[17] K. Tentsho, N. McNeil and P. Tongkumchum, "Examining timely graduation rates of undergraduate students.," Journal of Applied Research in Higher Education, pp. 199-209., 2019. 
